\title{
Quality of life and subjective sleep-related measures in bipolar disorder and major depressive disorder
}

\author{
Françoise Jermann ${ }^{1}\left[\right.$ D $\cdot$ Nader Perroud $^{1} \cdot$ Sophie Favre $^{1} \cdot$ Jean-Michel Aubry $^{1} \cdot$ Hélène Richard-Lepouriel $^{1}$
}

Accepted: 25 June 2021 / Published online: 14 July 2021

(c) The Author(s) 2021

\begin{abstract}
Purpose Diminished quality of life (QoL) has been reported in patients with mood disorders. QoL has also been shown to be decreased by sleep disturbances. Since sleep disorders are common in mood disorders, the aim of this study was to determine whether sleep characteristics are associated to QoL among patients with Bipolar Disorder (BD) and unipolar Major Depressive Disorders (MDD).

Methods QoL was assessed in 170 patients with mood disorders (61 BD and $109 \mathrm{MDD}$ ), who also completed questionnaires measuring the severity of insomnia, sleepiness, chronotype preference and obstructive sleep apnea (OSA) probability index. Results Analyses showed that BD and MDD groups had similar QoL and sleep measures but the MDD group had higher OSA scores. In BD, correlations indicated a relationship between $\mathrm{QoL}$ and insomnia complaints and sleepiness, whereas in MDD, correlations indicated an association between QoL and insomnia complaints and OSA score. In both groups, QoL was related to depressive symptomatology. Linear regressions showed that, in $\mathrm{BD}$, QoL was related to insomnia complaints and sleepiness even in the euthymic state, whereas in MDD, QoL was related to insomnia complaints but not in euthymic patients. Conclusion QoL is related to sleep differently in BD and MDD. The results suggest that insomnia and sleepiness are particularly high in BD even when patients are euthymic. These findings suggest that focusing on insomnia and sleepiness during different mood states of BD could increase QoL.
\end{abstract}

Keywords Quality of life · Sleep · Bipolar · Major depressive disorders

\section{Introduction}

Patients with bipolar disorders (BD) and major depressive disorders (MDD) report low quality of life (QoL) [1, 2]. There is no consensual definition of QoL in mood disorders but a recent thematic analyses in the domain of BD highlighted two dimensions: on the one hand, the evaluation of subjective experience, satisfaction, and well-being, and on the other hand, the observation of deviations from the standard in various domains of functioning (e.g., physical, mental, emotional, social, occupational, health) [3]. In this study, QoL corresponds to the satisfaction with life in specific domains that are central in $\mathrm{BD}$. These areas are related to clinical features (mood, sleep, health, cognition), pragmatic and functional outcomes (household, work, leisure, finances)

Françoise Jermann

francoise.jermann@hcuge.ch

1 Geneva University Hospitals, Geneva, Switzerland and personal or social-orientated constructs (social, selfesteem, spirituality, identity, independence). In mood disorders, poor QoL is correlated to depression severity but changes in mood symptomatology do not totally account for the variance in QoL [4] and poor QoL persists even in euthymic BD patients compared to controls [5].

Independently of mood disorders, poor QoL has also been shown in people presenting sleep disruptions, such as insomnia [6], sleepiness [7], obstructive sleep apnea (OSA) [8], and in people who have a preference for an evening chronotype [9]. These sleep particularities are common in both BD and MDD [10]. In BD patients, insomnia or hypersomnia is common during the depressive phase and continues even in the euthymic phase [11]. Moreover, it has been demonstrated that insomnia is a prodrome to both depressive onset and manic onset and is associated with more severe illness [12]. Sleepiness (decreased vigilance) has been described as excessive during depressive states in BD patients [13]. Patients with BD also have a preference for an evening chronotype [14] and have a high prevalence of OSA (24.5\%). 
Finally, regarding specifically the relation between QoL and sleep parameters in BD patients, it has been shown that sleep alteration (e.g., complaints, dissatisfaction with sleep, biological rhythm disruption) contributes to low QoL in symptomatic $[15,16]$ and euthymic BD patients [17]. Moreover, BD patients with abnormal sleep duration (short sleepers $<6 \mathrm{~h}$ or long sleepers $>9 \mathrm{~h}$ or $>10 \mathrm{~h}$ ) reported poorer QoL than BD patients with normal sleep duration $[18,19]$. This has however not been shown in euthymic BD patients [17].

MDD patients show similar sleep characteristics to BD patients. Indeed, insomnia is a frequent sleep disturbance during MDD and persists even after remission [20, 21]. Sleepiness [22] and evening chronotype [22] are also common in MDD and the prevalence of OSA (36.6\%) is even higher than that in BD patients [23].

In summary, QoL is low in people with mood disorders as well as those with sleep disturbances. The present study aimed to explore within a single trial the relation between QoL and sleep characteristics (insomnia complaints, sleepiness, chronotype, and risk for OSA) among individuals with $\mathrm{BD}$ or MDD.

\section{Method}

\section{Population}

One hundred and seventy participants were recruited from the outpatient Mood Disorder Unit at the Geneva University Hospitals. Each patient was assessed during three sessions by a psychiatrist and a psychologist specializing in adult mood disorders. Diagnoses were established according to the ICD-10 (International Classification of Diseases-10) criteria [10] and confirmed by the MINI (Mini-International Neuropsychiatric Interview)[24]. Current severity of depressive symptomatology was assessed with the Montgomery-Asberg Depressive rating scale (MADRS) [25] and hypo/manic symptoms with the Young Mania Rating Scale (YMRS) [26]. The assessments were carried out in French.

This study was approved by the ethics committee of the Geneva University Hospitals and informed written consent was obtained from all participants.

\section{Questionnaires}

Brief Quality of Life (Brief QoL.BD) [27]; French version: [28]). The QoL.BD and its short version (Brief QoL. $\mathrm{BD})$ were developed to measure $\mathrm{QoL}$ in BD. The authors assumed that some symptoms of BD could have a unique impact upon QoL and could be more sensitive to change than generic QoL measures. The QoL.BD and the Brief QoL.BD measure the subjective evaluation of well-being and the functioning dimension of QoL and was developed to be used in all BD mood states (depressive, hypomanic, euthymic). Twelve aspects of QoL-physical, sleep, mood, cognition, leisure, social, spirituality, finances, household, self-esteem, independence and identity-are rated on a five-point Likert scale (range 1-5). The total score ranges from 12 to 60, with higher scores representing better QoL.

Insomnia Severity Index (ISI) [29] French version: [30]). The ISI comprises seven items that are scored on a five-point Likert scale (range 0-4). The total score ranges from 0 to 28 , with higher scores indicating more insomnia complaints.

Epworth Sleepiness Scale (ESS) [31] French version: [32]. The ESS is composed of eight questions that are scored on a four-point Likert scale (range $0-3$ ) indicating the probability of falling asleep in different situations in daily life. The final score ranges from 0 to 24 . A score above 10 is considered to indicate excessive sleepiness.

Reduced version of the Horne and Östberg Morningness-Eveningness Questionnaire (rMEQ) [33] French version: [34]. The rMEQ is composed of five questions. The total score ranges from 4 to 25 , with a lower score indicating an evening preference and a higher score a morning preference.

STOP-Bang questionnaire [35] French version: [36]. The STOP-Bang questionnaire is composed of eight items assessing the risk factors for obstructive sleep apnea. Questions are scored on a yes/no scale. Each positive answer corresponds to one point (range 0-8). A higher score corresponds to a higher risk for OSA. A score of three or more indicates a moderate risk for OSA.

\section{Statistical analyses}

Statistics were computed using SPSS version 25 (IBM, Armonk, NY). QoL and variables related to sleep were all normally distributed (all skewness values were between -0.20 and 0.87 and kurtosis values were between -0.89 and 0.46). Differences between groups for demographic and clinical variables were tested with Student's $t$-tests and chisquare tests as appropriate. Associations between QoL, sleep measures and mood symptoms were tested with Pearson correlation coefficients. Multiple linear regressions were performed with QoL as dependent variable and sleep measures (insomnia symptoms, sleepiness, morningness-eveningness and risk for OSA) as independent variables. Analyses were performed separately for the BP and MDD groups. The same multiple linear regression analyses were then done on a subsample composed of only euthymic patients, defined with a MADRS score $<11$ and a YMRS score $<6$. Significance level was set at $p<0.05$. 


\section{Results}

Demographic, clinical and psychometric data are presented in Table 1. There are no significant differences between patients with BD and MDD for demographic data and for QoL and sleep measures (insomnia, sleepiness, morningness-eveningness) except for the risk for OSA and BMI, which are higher in the MDD than the BD group
(Table 1). For each group, the type of psychotropic drugs taken are presented in Table 1 (15\% of the participants in the BD group and $24 \%$ in the MDD group didn't take any psychotropic drug $-X^{2}=1.98 ; p=0.16$ ). Given the variety of molecules and dosage, this information is descriptive and could not be included in the analyses.

Pearson correlations between QoL and sleep measures are displayed in Table 2. Among patients with BD, there are significant relations between QoL and insomnia complaints

Table 1 Demographic and clinical characteristics and psychometric data (mean-SD) for patients with BD and MDD

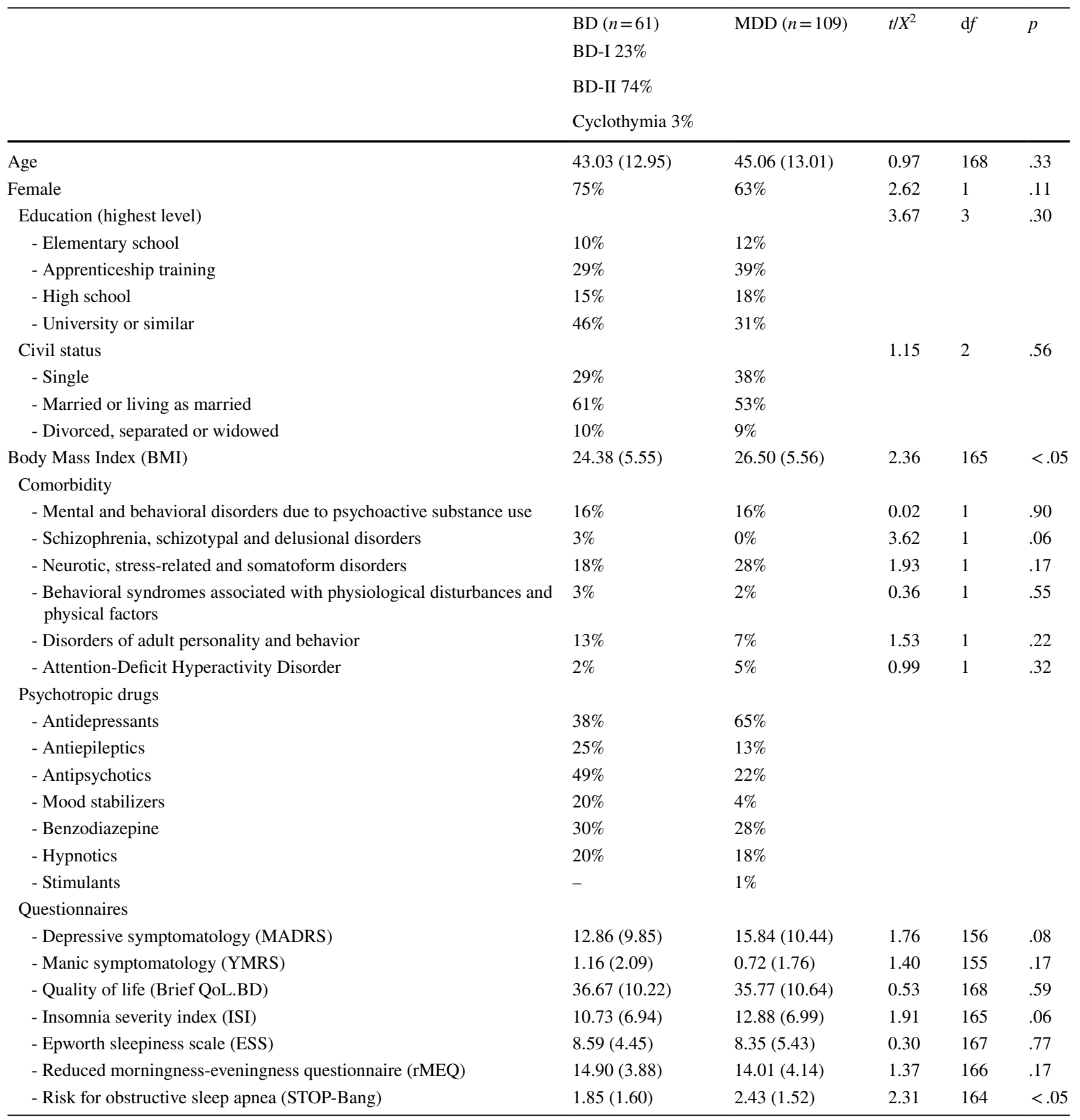


Table 2 Pearson correlations between QoL, sleep measures and mood symptoms and multiple linear regressions with QoL as dependent variable for $\mathrm{BD}$ and MDD

\begin{tabular}{|c|c|c|c|c|c|c|c|c|c|}
\hline & \multicolumn{5}{|l|}{ Correlations } & \multicolumn{4}{|c|}{ Multiple linear regressions } \\
\hline & \multirow[t]{2}{*}{ Brief QoL.BD } & \multirow[t]{2}{*}{ ISI } & \multirow[t]{2}{*}{ ESS } & \multirow[t]{2}{*}{ rMEQ } & \multirow[t]{2}{*}{ STOP-Bang } & \multirow[t]{2}{*}{ Beta } & \multirow[t]{2}{*}{$p$} & \multicolumn{2}{|l|}{$95 \% \mathrm{CI}$} \\
\hline & & & & & & & & Lower & Upper \\
\hline \multicolumn{10}{|l|}{ BD } \\
\hline ISI & $-.45^{* *}$ & - & & & & -.05 & .000 & -1.08 & -0.40 \\
\hline ESS & $-.27 *$ & -.15 & - & & & -.33 & .008 & -1.31 & -0.21 \\
\hline rMEQ & .10 & -.22 & .02 & - & & -.01 & .96 & -0.62 & 0.58 \\
\hline STOP-Bang & -.18 & .07 & $.36^{* *}$ & -.09 & - & -.03 & .81 & -1.71 & 1.35 \\
\hline MADRS & $-.58 * *$ & $.31 *$ & .07 & -.11 & .06 & & & & \\
\hline YMRS & .24 & .07 & -.20 & .05 & -.04 & & & & \\
\hline \multicolumn{10}{|l|}{ MDD } \\
\hline ISI & $-.31 * *$ & - & & & & -.32 & .001 & -0.77 & -0.20 \\
\hline ESS & -.11 & .16 & - & & & -.13 & .17 & -0.61 & 0.11 \\
\hline rMEQ & .02 & -.02 & -.07 & - & & .03 & .74 & -0.38 & 0.53 \\
\hline STOP-Bang & $-.20 *$ & .17 & $.23^{*}$ & .11 & - & -.14 & .17 & -2.29 & 0.41 \\
\hline MADRS & $-.64 * *$ & $.34 * *$ & -.08 & .01 & $.24^{*}$ & & & & \\
\hline YMRS & .17 & .15 & .06 & .07 & .02 & & & & \\
\hline
\end{tabular}

Brief QoL.BD quality of life; ISI: insomnia severity index, ESS epworth sleepiness scale, $r M E Q$ reduced version of the Horne and Ostberg Morningness-Eveningness Questionnaire, STOP-Bang risk factors for obstructive sleep apnea - STOP-Bang questionnaire, MADRS montgomery-asberg depression rating scale, YMRS young mania rating scale, $*<.05 ; * *<.01 ; 95 \%$ CI 95\% confidence interval and sleepiness. In the MDD group, QoL was negatively correlated with insomnia complaints and the risk for OSA. In both groups, QoL was negatively associated with depressive symptomatology. Depressive symptomatology was also positively correlated with insomnia symptoms (both groups) and the risk for OSA (MDD group). There was, however, no significant correlation between QoL and age for the BD $(\mathrm{r}=-0.01 ; p=0.94)$ or MDD groups $(\mathrm{r}=-0.03 ; p=0.78)$ and no significant difference in QoL score across gender in either group $(\mathrm{BD}: \mathrm{t}(59)=0.78 ; p=44$; MDD: $\mathrm{t}(107)=$ $-1.19 ; p=0.24)$.

To evaluate whether sleep variables are related to QoL, multiple linear regressions were conducted for both groups. Underlying assumptions required for regressions analyses were all met (linearity, multicollinearity, normality of residuals, and homoscedasticity of residuals). In the BD group, the lowest tolerance value was 0.84 and the highest VIF value was 1.19 , Durbin-Watson $=1.56$, maximum Cook's distance value was 0.11 . In the MDD group, the lowest tolerance value was 0.90 and the highest VIF value was 1.12 , Durbin-Watson $=1.81$, maximum Cook's distance value was 0.08. In patients with BD, QoL was explained by insomnia complaints and sleepiness. In MDD, QoL was related only to insomnia complaints (Table 2).

To rule out the impact of actual depressive or hypo/ manic symptomatology, participants with BD and MDD in a euthymic state were compared (Table 3). Student's $t$-tests showed that euthymic patients with BD and MDD did not differ neither regarding QoL nor for the sleep variables (see
Table 3). Multiple linear regressions were conducted with QoL as dependent variable and sleep measures as predictors; the results indicated that, for euthymic patients with BD, QoL was related to insomnia complaints and sleepiness, whereas for euthymic patients with MDD, sleep parameters did not affect QoL (Table 3, 4).

\section{Discussion}

This study investigated the relationship of QoL and sleep in patients with mood disorders. The patients with BD and MDD reported similar QoL and sleep characteristics (insomnia complaints, sleepiness, morningness-eveningness), although the MDD group displayed a higher risk for OSA than the BD group. There were significant negative correlations between QoL and depressive symptomatology in both groups, as well as between QoL and insomnia and sleepiness in BD and QoL, and insomnia and risk for OSA in MDD. Finally, the results showed that, in patients with BD, QoL was related to insomnia complaints and sleepiness level, whereas in MDD patients only insomnia complaints were associated to QoL. Considering only euthymic patients, insomnia complaints and sleepiness were still related to QoL in BD, whereas in MDD, QoL was not associated to any sleep parameters.

In patients with $\mathrm{BD}$, QoL is related to insomnia complaints and sleepiness even in the euthymic state. These results are particularly interesting as they bring together 
Table 3 Demographic characteristics, psychometric data (mean-SD) for the euthymic subsample of patients with BD and MDD

\begin{tabular}{|c|c|c|c|c|c|}
\hline & Euthymic BD $(n=25)$ & Euthymic MDD $(n=32)$ & $t / X^{2}$ & $\mathrm{~d} f$ & $p$ \\
\hline Age & $44.52(10.89)$ & $42.78(11.79)$ & 0.57 & 55 & .57 \\
\hline Female & $68 \%$ & $66 \%$ & 0.04 & 1 & .85 \\
\hline Education (highest level) & & & 0.76 & 3 & .86 \\
\hline - Elementary school & $12 \%$ & $6 \%$ & & & \\
\hline - Apprenticeship training & $40 \%$ & $38 \%$ & & & \\
\hline - High school & $12 \%$ & $12 \%$ & & & \\
\hline - University or similar & $36 \%$ & $44 \%$ & & & \\
\hline Civil status & & & 0.64 & 2 & .73 \\
\hline - Single & $28 \%$ & $25 \%$ & & & \\
\hline - Married or living as married & $68 \%$ & $66 \%$ & & & \\
\hline - Divorced, separated or widowed & $4 \%$ & $9 \%$ & & & \\
\hline \multicolumn{6}{|l|}{ Questionnaires } \\
\hline - Quality of life (Brief QoL.BD) & $41.08(9.11)$ & $43.66(8.84)$ & -1.08 & 55 & .29 \\
\hline - Insomnia severity index (ISI) & $9.50(6.36)$ & $9.60(6.22)$ & -0.06 & 55 & .95 \\
\hline - Epworth sleepiness scale (ESS) & $9.56(4.70)$ & $8.16(5.10)$ & 1.07 & 55 & .29 \\
\hline $\begin{array}{l}\text { - Reduced morningness-eveningness } \\
\text { questionnaire (rMEQ) }\end{array}$ & $15.32(3.92)$ & $14.23(3.85)$ & 1.05 & 55 & .30 \\
\hline $\begin{array}{l}\text { - Risk for obstructive sleep apnea } \\
\text { (STOP-Bang) }\end{array}$ & $2.08(1.78)$ & $2.03(1.65)$ & 1.01 & 53 & .92 \\
\hline
\end{tabular}

Table 4 Multiple linear regressions with QoL as dependent variable for the euthymic subsample of patients with BD and MDD

\begin{tabular}{lcllr}
\hline $\begin{array}{l}\text { Multiple linear } \\
\text { regressions }\end{array}$ & Beta & $p$ & \multicolumn{2}{l}{$95 \%$ CI } \\
\cline { 4 - 5 } & & & Lower & Upper \\
\hline BD & & & & \\
ISI & -.52 & .005 & -1.24 & -0.25 \\
ESS & -.53 & .007 & -1.74 & -0.32 \\
rMEQ & .004 & .98 & -0.79 & 0.81 \\
STOP-Bang & .28 & .12 & -0.39 & 3.29 \\
MDD & & & & \\
ISI & -.30 & .16 & -0.92 & 0.16 \\
ESS & .03 & .88 & -0.63 & 0.73 \\
rMEQ & .001 & .99 & -0.79 & 0.80 \\
STOP-Bang & -.11 & .61 & -2.65 & 1.59 \\
\hline
\end{tabular}

Brief QoL.BD Quality of life, ISI Insomnia Severity Index, ESS, Epworth Sleepiness Scale, $r M E Q$ reduced version of the Horne and Ostberg Morningness-Eveningness Questionnaire, STOP-Bang risk factors for obstructive sleep apnea-STOP-Bang questionnaire, $*<.05 ; * *<.01 ; 95 \%$ CI $95 \%$ confidence interval

research showing, on the one hand, that $\mathrm{QoL}$ is associated to insomnia or sleepiness $[6,7]$ and, on the other hand, that patients with BD complain of insomnia and sleepiness [11, 13]. Moreover, the results are also congruent with prior studies showing that altered sleep parameters are related to low QoL in BD patients [15, 16, 18, 19]. The relationship between QoL and sleepiness is especially interesting as it could be related to some of the pharmacological treatments used to treat BD (e.g., antipsychotics) but also to possible impairment in daily functioning in BD (e.g., impaired occupational, cognitive, interpersonal functioning) [37]. Further studies should be conducted to specifically evaluate the relationship between QoL, sleepiness, the use of sedatives and functional impairment.

The analyses showing a relationship between QoL and insomnia in BD are an invitation to consider specific interventions to reduce insomnia and sleepiness during different stages of the disorder (depressive and euthymic). To date, some studies evaluated Cognitive Behavioral Therapy for Insomnia (CBT-I) among BD patients and showed positive effects on reducing insomnia [e.g., 38, 39, 40]. However, data regarding CBT-I in BD are still scarce probably because the intervention requires spending less time in bed; this is sometimes interpreted as shortening sleep duration, which is known to be a risk factor for the onset of hypo/manic episodes [41]. Today, the recommendation for BD patients who undergo CBT-I is that depressive and hypo/manic symptoms are monitored at every session and sleep restriction suspended in case of symptom change $[42,43]$.

Considering patients with MDD, this study shows that QoL is related to insomnia and the risk for OSA. These results are in accordance with past findings demonstrating both that insomnia and OSA are frequent in MDD [21, 23] and that insomnia and OSA are related to decreased QoL [6, 8]. Moreover, these results are an important reminder for clinicians to 
systematically screen MDD patients for the risk for OSA, given that it is associated with perturbed sleep and impaired physical health (e.g., obesity, cardiovascular diseases). It is also an invitation to be particularly careful about the pharmacological treatments used for MDD, as side effects include weight gain, which is a factor contributing to the risk for OSA. Our results showed that QoL is only related to insomnia in a sample including a whole range of depressive symptoms but not when patients with MDD are in a euthymic state; this suggests that the relation is mood-dependent. In other words, QoL seems to be related to insomnia when there is current depressive symptomatology.

\section{Limitations}

This study has several strengths: a relatively large sample of thoroughly diagnosed patients with mood disorders and a variety of sleep characteristic measures. Still, some limitations must be acknowledged. First, even though the data are based on validated self-report questionnaires, measuring sleep parameters with objective tools (e.g., wrist actigraphy) or daily sleep diaries could have added further information. Second, the majority of the sample was taking medications, which could have affected their sleep and/or arousal level. Given the diversity of molecules and dosage among the sample, this dimension could not be taken into account in the analyses. However, the use of medication might be a mediator between QoL and sleep characteristics and then affect differently the relation for BD and MDD. Therefore, further studies should take this variable into account. Third, QoL was measured with a questionnaire specifically developed to assess QoL in BD whereas the sample also included patients with MDD. However, the data indicated that internal consistencies were similar in both groups (Cronbach's alpha of 0.88 and 0.89 , respectively) and there was also no difference between groups at an item level (all ps $>0.13$ ).

\section{Conclusion}

The results of this study suggest that in BD there is a link between QoL and insomnia complaints and sleepiness during the acute and euthymic phases of the disorder. These results have important implications for clinical practice as they encourage clinicians to evaluate insomnia complaints and sleepiness but also to suggest specific interventions for insomnia and sleepiness, not only during the acute phase of the disorder but also in the euthymic phase.

Funding Open Access funding provided by Université de Genève. This research did not receive any specific grant from funding agencies in the public, commercial, or not-for-profit sectors.

\section{Declarations}

Conflict of interest The authors declare that there is no conflict of interest.

Open Access This article is licensed under a Creative Commons Attribution 4.0 International License, which permits use, sharing, adaptation, distribution and reproduction in any medium or format, as long as you give appropriate credit to the original author(s) and the source, provide a link to the Creative Commons licence, and indicate if changes were made. The images or other third party material in this article are included in the article's Creative Commons licence, unless indicated otherwise in a credit line to the material. If material is not included in the article's Creative Commons licence and your intended use is not permitted by statutory regulation or exceeds the permitted use, you will need to obtain permission directly from the copyright holder. To view a copy of this licence, visit http://creativecommons.org/licenses/by/4.0/.

\section{References}

1. Michalak, E. E., Yatham, L. N., \& Lam, R. W. (2005). Quality of life in bipolar disorder: A review of the literature. Health and Quality of Life Outcomes, 3, 72. https://doi.org/10.1186/ 1477-7525-3-72

2. Ishak, W. W., Balayan, K., Bresee, C., Greenberg, J. M., Fakhry, H., Christensen, S., \& Rapaport, M. H. (2013). A descriptive analysis of quality of life using patient-reported measures in major depressive disorder in a naturalistic outpatient setting. Quality of Life Research, 22(3), 585-596. https://doi.org/10. 1007/s11136-012-0187-6

3. Morton, E., Michalak, E. E., \& Murray, G. (2017). What does quality of life refer to in bipolar disorders research? A systematic review of the construct's definition, usage and measurement. Journal of Affective Disorders, 212, 128-137. https://doi. org/10.1016/j.jad.2017.01.026

4. Hofmann, S. G., Curtiss, J., Carpenter, J. K., \& Kind, S. (2017). Effect of treatments for depression on quality of life: A metaanalysis. Cognitive Behaviour Therapy, 46(4), 265-286. https:// doi.org/10.1080/16506073.2017.1304445

5. Pascual-Sanchez, A., Jenaro, C., \& Montes-Rodriguez, J. M. (2019). Quality of life in euthymic bipolar patients: A systematic review and meta-analysis. Journal of Affective Disorders, 255, 105-115. https://doi.org/10.1016/j.jad.2019.05.032

6. Kyle, S. D., Morgan, K., \& Espie, C. A. (2010). Insomnia and health-related quality of life. Sleep Medicine Reviews, 14(1), 69-82. https://doi.org/10.1016/j.smrv.2009.07.004

7. Belayachi, J., Benjelloun, O., Madani, N., Abidi, K., Dendane, T., Zeggwagh, A. A., \& Abouqal, R. (2013). Self-perceived sleepiness in emergency training physicians: prevalence and relationship with quality of life. Journal of Occupational Medicine and Toxicology, 8(1), 24. https://doi.org/10.1186/ 1745-6673-8-24

8. Moyer, C. A., Sonnad, S. S., Garetz, S. L., Helman, J. I., \& Chervin, R. D. (2001). Quality of life in obstructive sleep apnea: A systematic review of the literature. Sleep Medicine, 2(6), 477-491. https://doi.org/10.1016/s1389-9457(01)00072-7

9. Sasawaki, Y., \& Shiotani, H. (2019). The influence of chronotype and working condition on sleep status and health related quality of life of daytime office workers. The Kobe Journal of Medical Sciences, 64(5), E189-E196. 
10. World Health Organisation (Ed.). (1993). The ICD-10 classification of mental and behavioural disorders: diagnostic criteria for research. Geneva: World Health Organisation

11. Soehner, A. M., Kaplan, K. A., \& Harvey, A. G. (2013). Insomnia comorbid to severe psychiatric illness. Sleep Medicine Clinics, 8(3), 361-371. https://doi.org/10.1016/j.jsmc.2013.04.007

12. Pancheri, C., Verdolini, N., Pacchiarotti, I., Samalin, L., DelleChiaie, R., Biondi, M., Carvalho, A. F., Valdes, M., Ritter, P., Vieta, E., \& Murru, A. (2019). A systematic review on sleep alterations anticipating the onset of bipolar disorder. European Psychiatry, 58, 45-53. https://doi.org/10.1016/j.eurpsy.2019.02.003

13. Stroe, A. F., Roth, T., Jefferson, C., Hudgel, D. W., Roehrs, T., Moss, K., \& Drake, C. L. (2010). Comparative levels of excessive daytime sleepiness in common medical disorders. Sleep Medicine, 11(9), 890-896. https://doi.org/10.1016/j.sleep.2010.04.010

14. Melo, M. C. A., Abreu, R. L. C., LinharesNeto, V. B., de Bruin, P. F. C., \& de Bruin, V. M. S. (2017). Chronotype and circadian rhythm in bipolar disorder: A systematic review. Sleep Medicine Reviews, 34, 46-58. https://doi.org/10.1016/j.smrv.2016.06.007

15. Giglio, L. M., Andreazza, A. C., Andersen, M., Cereser, K. M., Walz, J. C., Sterz, L., \& Kapczinski, F. (2009). Sleep in bipolar patients. Sleep Breath, 13(2), 169-173. https://doi.org/10.1007/ s11325-008-0215-5

16. Slyepchenko, A., Allega, O. R., Leng, X., Minuzzi, L., Eltayebani, M. M., Skelly, M., Sassi, R. B., Soares, C. N., Kennedy, S. H., \& Frey, B. N. (2019). Association of functioning and quality of life with objective and subjective measures of sleep and biological rhythms in major depressive and bipolar disorder. The Australian and New Zealand Journal of Psychiatry, 53(7), 683-696. https:// doi.org/10.1177/0004867419829228

17. De la Fuente-Tomas, L., Sierra, P., Sanchez-Autet, M., GarciaBlanco, A., Safont, G., Arranz, B., \& García-Portilla, M. P. (2018). Sleep disturbances, functioning, and quality of life in euthymic patients with bipolar disorder. Psychiatry Research, 269, 501-507. https://doi.org/10.1016/j.psychres.2018.08.104

18. Bradley, A. J., Webb-Mitchell, R., Hazu, A., Slater, N., Middleton, B., Gallagher, P., McAllister-Williams, H., \& Anderson, K. N. (2017). Sleep and circadian rhythm disturbance in bipolar disorder. Psychological Medicine, 47(9), 1678-1689. https://doi.org/ 10.1017/S0033291717000186

19. Gruber, J., Harvey, A. G., Wang, P. W., Brooks, J. O., 3rd., Thase, M. E., Sachs, G. S., \& Ketter, T. A. (2009). Sleep functioning in relation to mood, function, and quality of life at entry to the Systematic Treatment Enhancement Program for Bipolar Disorder (STEP-BD). Journal of Affective Disorders, 114(1-3), 41-49. https://doi.org/10.1016/j.jad.2008.06.028

20. Baglioni, C., Battagliese, G., Feige, B., Spiegelhalder, K., Nissen, C., Voderholzer, U., Lombardo, C., \& Riemann, D. (2011). Insomnia as a predictor of depression: a meta-analytic evaluation of longitudinal epidemiological studies. Journal of Affective Disorders, 135(1-3), 10-19. https://doi.org/10.1016/j.jad.2011. 01.011

21. Taylor, D. J., Lichstein, K. L., Durrence, H. H., Reidel, B. W., \& Bush, A. J. (2005). Epidemiology of insomnia, depression, and anxiety. Sleep, 28(11), 1457-1464. https://doi.org/10.1093/sleep/ 28.11.1457

22. Au, J., \& Reece, J. (2017). The relationship between chronotype and depressive symptoms: A meta-analysis. Journal of Affective Disorders, 218, 93-104. https://doi.org/10.1016/j.jad.2017.04.021

23. Stubbs, B., Vancampfort, D., Veronese, N., Solmi, M., Gaughran, F., Manu, P., Rosenbaum, S., De Hert, M., \& Fornaro, M. (2016). The prevalence and predictors of obstructive sleep apnea in major depressive disorder, bipolar disorder and schizophrenia: A systematic review and meta-analysis. Journal of Affective Disorders, 197, 259-267. https://doi.org/10.1016/j.jad.2016.02.060
24. Sheehan, D. V., Lecrubier, Y., Sheehan, K. H., Amorim, P., Janavs, J., Weiller, E., Hergueta, T., Baker, R., \& Dunbar, G. C. (1998). The Mini-International Neuropsychiatric Interview (M.I.N.I.): The development and validation of a structured diagnostic psychiatric interview for DSM-IV and ICD-10. The Journal of Clinical Psychiatry, 59(Suppl 20), 22-33. quiz 34-57.

25. Montgomery, S. A., \& Asberg, M. (1979). A new depression scale designed to be sensitive to change. The British Journal of Psychiatry, 134, 382-389. https://doi.org/10.1192/bjp.134.4.382

26. Young, R. C., Biggs, J. T., Ziegler, V. E., \& Meyer, D. A. (1978). A rating scale for mania: Reliability, validity and sensitivity. The British Journal of Psychiatry, 133, 429-435. https://doi.org/10. 1192/bjp.133.5.429

27. Michalak, E. E., Murray, G., \& Collaborative RESearch Team to Study Psychosocial Issues in Bipolar Disorder (CREST.BD). (2010). Development of the QoL.BD: A disorder-specific scale to assess quality of life in bipolar disorder. Bipolar Disorders, 12(7), 727-740. https://doi.org/10.1111/j.1399-5618.2010.00865.x

28. Provencher, M. D., Morton, E., Beaudoin, A. S., Guillemette, J., Rheault, E., Mérette, C., Coque, L., Hawke, L. D., \& Michalak, E. E. (2020). The Quality of Life in Bipolar Disorder (QoL.BD) Scale: Validation of a french cross-cultural adaptation: L'echelle de qualite de vie dans le trouble bipolaire (QoL.BD): Validation d'une adaptation francaise interculturelle. Canadian Journal of Psychiatry Revue Canadienne de Psychiatrie. https://doi.org/10. 1177/0706743720948663

29. Morin, C. M., Belleville, G., Belanger, L., \& Ivers, H. (2011). The insomnia severity index: Psychometric indicators to detect insomnia cases and evaluate treatment response. Sleep, 34(5), 601-608. https://doi.org/10.1093/sleep/34.5.601

30. Blais, F. C., Gendron, L., Mimeault, V., \& Morin, C. M. (1997). Evaluation de l'insomnie: Validation de trois questionnaires. Encephale, 23(6), 447-453.

31. Johns, M. W. (1991). A new method for measuring daytime sleepiness: The Epworth sleepiness scale. Sleep, 14(6), 540-545. https:// doi.org/10.1093/sleep/14.6.540

32. Kaminska, M., Jobin, V., Mayer, P., Amyot, R., Perraton-Brillon, M., \& Bellemare, F. (2010). The Epworth sleepiness scale: Selfadministration versus administration by the physician, and validation of a French version. Canadian Respiratory Journal, 17(2), e27-34. https://doi.org/10.1155/2010/438676

33. Adan, A., \& Almirall, H. (1991). Horne \& Östberg morningnesseveningness questionnaire: A reduced scale. Personality and Individual differences, 12(3), 241-253.

34. Taillard, J., Philip, P., Chastang, J. F., \& Bioulac, B. (2004). Validation of Horne and Ostberg morningness-eveningness questionnaire in a middle-aged population of French workers. Journal of Biological Rhythms, 19(1), 76-86. https://doi.org/10.1177/07487 30403259849

35 Chung, F., Yegneswaran, B., Liao, P., Chung, S. A., Vairavanathan, S., Islam, S., Khajehdehi, A., \& Shapiro, C. M. (2008). STOP questionnaire: a tool to screen patients for obstructive sleep apnea. Anesthesiology, 108(5), 812-821. https://doi.org/10.1097/ ALN.0b013e31816d83e4

36. University Health Network, University of Toronto, \& Toronto Western Hospital (2015). Questionnaire STOP-Bang mis à jour (version française). http://www.stopbang.ca/translation/pdf/frenc hfr.pdf. Accessed 26 Feb 2021.

37. Duarte, W., Becerra, R., \& Cruise, K. (2016). The relationship between neurocognitive functioning and occupational functioning in bipolar disorder: A literature review. Europe's Journal of Psychology, 12(4), 659-678. https://doi.org/10.5964/ejop.v12i4. 909

38. Harvey, A. G., Soehner, A. M., Kaplan, K. A., Hein, K., Lee, J., Kanady, J., Li, D., Rabe-Hesketh, S., Ketter, T. A., Neylan, T. C., \& Buysse, D. J. (2015). Treating insomnia improves mood state, 
sleep, and functioning in bipolar disorder: a pilot randomized controlled trial. Journal of Consulting and Clinical Psychology, 83(3), 564-577. https://doi.org/10.1037/a0038655

39. Sandlund, C., Hetta, J., Nilsson, G. H., Ekstedt, M., \& Westman, J. (2018). Impact of group treatment for insomnia on daytime symptomatology: Analyses from a randomized controlled trial in primary care. International Journal of Nursing Studies, 85, 126-135. https://doi.org/10.1016/j.ijnurstu.2018.05.002

40. Kaplan, K. A., \& Harvey, A. G. (2013). Behavioral treatment of insomnia in bipolar disorder. The American Journal of Psychiatry, 170(7), 716-720. https://doi.org/10.1176/appi.ajp.2013.12050708

41. Lewis, K. S., Gordon-Smith, K., Forty, L., Di Florio, A., Craddock, N., Jones, L., \& Jones, I. (2017). Sleep loss as a trigger of mood episodes in bipolar disorder: Individual differences based on diagnostic subtype and gender. The British Journal of Psychiatry, 211(3), 169-174. https://doi.org/10.1192/bjp.bp.117.202259

42. Garland, S. N., Vargas, I., Grandner, M. A., \& Perlis, M. L. (2018). Treating insomnia in patients with comorbid psychiatric disorders: A focused review. Canadian Psychology/Psychologie canadienne, 59(2), 176-186. https://doi.org/10.1037/cap0000141

43. Morton, E., \& Murray, G. (2020). Assessment and treatment of sleep problems in bipolar disorder-A guide for psychologists and clinically focused review. Clinical Psychology \& Psychotherapy, 27(3), 364-377. https://doi.org/10.1002/cpp.2433

Publisher's Note Springer Nature remains neutral with regard to jurisdictional claims in published maps and institutional affiliations. 